\title{
Negative Skin Test
}

National Cancer Institute

\section{Source}

National Cancer Institute. Negative Skin Test. NCI Thesaurus. Code C35627.

A finding that indicates the absence of an immune response to an antigen that is introduced to the skin. 